\title{
Therapeutic effectiveness of instrument-assisted soft tissue mobilization for soft tissue injury: mechanisms and practical application
}

\author{
Jooyoung Kim', Dong Jun Sung'², Joohyung Lee ${ }^{1, *}$ \\ ${ }^{1}$ Sport, Health and Rehabilitation Major, College of Physical Education, Kookmin University, Seoul, Korea \\ ${ }^{2}$ Division of Sport Science, College of Science and Technology, Konkuk University, Chungju, Korea
}

This article reviews the mechanism and effects of instrument-assisted soft tissue mobilization (IASTM), along with guidelines for its practical application. IASTM refers to a technique that uses instruments to remove scar tissues from injured soft tissues and facilitate healing process through formation of new extracellular matrix proteins such as collagen. Recently, frequent use of this instrument has increased in the fields of sports rehabilitation and athlete training. Some experimental studies and case reports have reported that IASTM can significantly improve soft tissue function and range of motion following sports injury, while also reducing pain. Based on the previous studies, it is thought that IASTM can help shorten the rehabilitation period and time to return to sports among athletes and ordinary people who have suffered sports injuries. However, few experimental studies of the mechanisms and effects of IASTM have examined, while case reports have accounted for the majority of articles. In the future, the scientific basis of IASTM and its reliability should be provided through well-designed experimental studies on humans. Moreover, IASTM studies that have mostly focused on tendons need to broaden their scope toward other soft tissues such as muscles and ligaments.

Keywords: Injury, Instrument-assisted soft tissue mobilization, Pain, Range of motion, Soft tissue function

\section{INTRODUCTION}

In today's society, a large proportion of the population participates in exercise. However, when the general public overexert themselves with high-intensity exercise or long periods of exercise with poor posture, injuries to the soft tissues, such as muscles, ligaments, and tendons, can occur (Hart, 1994; Yeung and Yeung, 2001). Because sports injuries reduce soft tissue function and increase pain, they can have a negative impact on maintaining one's optimal conditioning. Therefore, rehabilitation after a sports injury is critical, and several interventions have been proposed to help the process of healing. These include electroacupuncture, extracorporeal shockwave therapy, hyperbaric oxygen therapy, laser therapy, prolotherapy, and whole body cryotherapy (Barata et al., 2011; Costello et al., 2015; Delbari et al., 2007; Inoue et al.,
2015; Steinacker and Steuer, 2001; Topol et al., 2005). However, some of these methods require expensive equipment and their effectiveness is still being debated.

Recently, instrument-assisted soft tissue mobilization (IASTM) has received much attention. IASTM is a technique that involves using instruments to address musculoskeletal pathology-related impairments and help heal soft tissues (Kivlan et al., 2015; Sevier and Stegink-Jansen, 2015). When a stimulus is applied to the injured soft tissue using an instrument, the activity and the number of fibroblasts increase, along with fibronectin, through localized inflammation, which then facilitates the synthesis and realignment of collagen is one of the proteins that makes up the extracellular matrix (Davidson et al., 1997; Gehlsen et al., 1999; Hammer, 2008). Some studies have reported that IASTM can reduce pain caused due to sports injury and improve soft tissue function
${ }^{*}$ Corresponding author: Joohyung Lee (iD http://orcid.org/0000-0001-8279-3830 Sport, Health and Rehabilitation Major, College of Physical Education, Kookmin University, 77 Jeongneung-ro, Seongbuk-gu, Seoul 02707, Korea Tel: +82-2-910-5254, Fax: +82-2-910-4789, E-mail: jolee@kookmin.ac.kr Received: October 14, 2016 / Accepted: January 6, 2017
This is an Open Access article distributed under the terms of the Creative Commons Attribution Non-Commercial License (http://creativecommons.org/licenses/by-nc/4.0/) which permits unrestricted non-commercial use, distribution, and reproduction in any medium, provided the original work is properly cited. 
and joint range of motion (ROM) (Howitt et al., 2009; Miners and Bougie, 2011; Schaefer and Sandrey, 2012). Howitt et al. (2009) reported that when applied to a triathlete who had suffered an acute grade 1 strain in the tibialis posterior muscle, IASTM was able to reduce pain, while Schaefer and Sandrey (2012) indicated that IASTM improved ankle ROM in high school athletes with chronic ankle instability. Moreover, Miners and Bougie (2011) also reported that IASTM helped improve soft tissue function in ordinary people with chronic Achilles tendinopathy resulting from persistent running.

The results of the above mentioned studies demonstrate the fact that IASTM is effective in the treatment and rehabilitation of athletes and ordinary people who have sports injuries. If IASTM can be applied clinically, then it can help speed up healing following an injury and the successful return to sports or daily activities. Accordingly, the objective of the present study was to use previous studies as the basis to examine the mechanism and effects of IASTM and provide guidelines for its practical application.

\section{INSTRUMENT-ASSISTED SOFT TISSUE MOBILIZATION}

In ancient Greece and Rome, a small metallic instrument known as a "strigil" was used in bathhouses for therapeutic purposes (Hammer, 2008), and such an instrument has led to today's IASTM. Another origin of IASTM is a traditional Chinese therapy known as "gua sha" (Nielsen et al., 2007). The word "gua sha" refers to the red spot that appears on the skin when an instrument is used to push or scrape the skin, increasing the blood flow to facilitate the supply of blood and oxygen to the soft tissues (Chiu et al., 2010; Hammer, 2008). IASTM is based on these principles and it is a technique that is a modified version of traditional soft tissue mobilization, such as "gua sha." IASTM includes augmented soft tissue mobilization (Astym), fascial abrasion technique, Graston technique, and sound-assisted soft tissue mobilization (Hammer, 2008; Kivlan et al., 2015; Markovic, 2015), with different names referring to the different material or shape of the instrument used. While rocks, wooden sticks, and animal bones may have been used historically to apply a stimulus to the skin, various instruments made primarily of stainless steel are used today (Fig. 1).

IASTM is a simple and practical technique (Loghmani and Warden, 2009). Because the surface of the instrument minimizes the force used by the practitioner, but maximizes the force delivered to the tissues, it is possible to stimulate points of adhesion

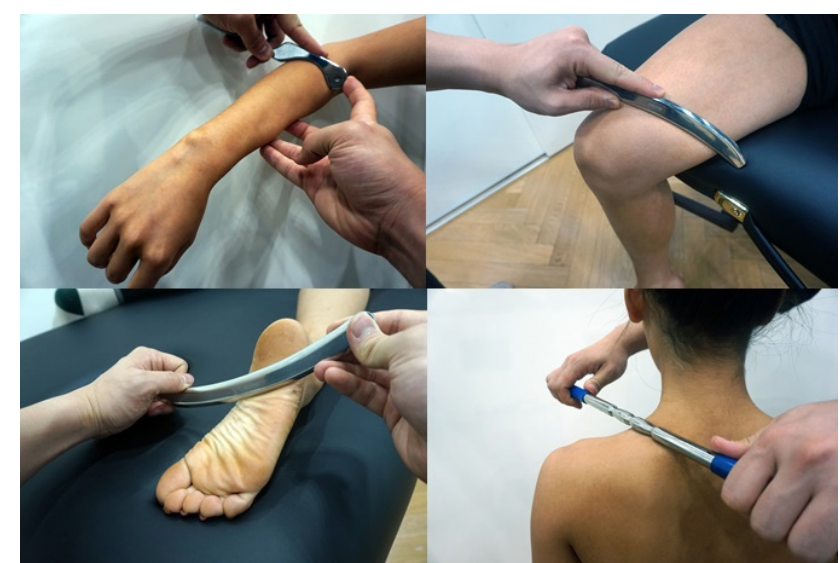

Fig. 1. Application of instrument-assisted soft tissue mobilization using stainless steels.

located in deep areas (Baker et al., 2013; Burke et al., 2007; Carey-Loghmani et al., 2010; Hammer, 2008; Hammer and Pfefer, 2005). Hayes et al. (2007) found that the levels of discomfort and fatigue experienced by therapists who treated patients with IASTM were significantly lower than the levels in therapists treating their patients using the metal end of a reflex hammer. Moreover, IASTM has another advantage of being able to produce positive effects in a much shorter period than friction massage, another mode of soft tissue therapy, which requires 15-20 min (Hammer, 2008). Currently, IASTM (especially the Graston technique) is included in the curriculum of physical therapy and chiropractic in some American colleges, while its use in the fields of sports rehabilitation and athlete training is also increasing.

\section{Mechanism of IASTM}

In sports, soft tissue injuries can occur from excessive tension or overuse (Hart, 1994; Yeung and Yeung, 2001). After an injury, inflammation and proliferation of new cells occur, during which fibrosis and formation of scar tissue in the injured soft tissue may occur (Sato et al., 2003). These changes reduce tissue elasticity and cause adhesion, which can lead to diminished soft tissue function and pain (Huard et al., 2002; Melham et al., 1998). In particular, scar tissue limits perfusion to the injured soft tissue, restricting the supply of oxygen and nutrients, and interferes with collagen synthesis and regeneration of tissues, which may then cause incomplete functional recovery (Chen and Li, 2009; Gauglitz et al., 2011). These alterations also increase the risk of reinjury (Huard et al., 2002).

The biggest goal of IASTM is to remove scar tissues and promote a return to normal function following soft tissue regenera- 
tion (Gehlsen et al., 1999; Melham et al., 1998). When the scar tissue is removed by IASTM, functional normalization around the soft tissue can be achieved (Black, 2010). Microvascular and capillary hemorrhage, along with localized inflammation, can occur as a result of using IASTM to apply appropriate pressure and shear force to the soft tissue. Such inflammation restarts the healing process by removing the scar tissue and releasing adhesions, while also increasing blood and nutrient supply to the injured area and migration of fibroblasts (Baker et al., 2013; Davidson et al., 1997; Gehlsen et al., 1999; Hammer, 2008). Ultimately, new collagen is synthesized and realigned, which enables the turnover and regeneration of the injured tissue (Davies and Backopp, 2010; Gehlsen et al., 1999).

This hypothesis has been supported by some animal and human studies. Davidson et al. (1997) applied IASTM to the Achilles tendon in a rat model with enzyme-induced injury and found that earlier recovery of limb function was facilitated by a significant increase in the recruitment and activation of fibroblasts. Moreover, Gehlsen et al. (1999) also reported that when IASTM was applied to rats with enzyme-induced injury of the Achilles tendon, a significantly increased number of fibroblasts were observed in the tissue samples under electron microscopy. In other words, because IASTM affects fibroblasts, it was able to accelerate the healing of injured tendons. Fibroblasts are associated with collagen synthesis (Davidson et al., 1997; Gehlsen et al., 1999). Tropocollagen produced by fibroblasts acts as a precursor to collagen (Church et al., 1971). Collagen deformation in soft tissues is one of the causes of delayed healing, while IASTM has a positive impact on the resynthesis and organization of collagen (Davidson et al., 1997; Gehlsen et al., 1999).

Such changes to collagen require fibronectin (Lehto et al., 1985), the levels of which are increased by IASTM. Fibronectin is a noncollagenous glycoprotein that moves like adhesion molecules that connect collagen and cells, is synthesized by fibroblasts and epithelial cells, and is essential for tissue formation and repair (Lenselink, 2015). According to one study, applying IASTM to the tendons of injured rats showed increased fibronectin staining (Davidson et al., 1997). In contrast, not applying any treatment after an injury can result in disorganized collagen alignment in the soft tissue and formation of scar tissue. Loghmani and Warden (2009) reported that applying IASTM to rats with an injury to the medial collateral ligament (MCL) of the knee resulted in quicker healing than that in the untreated ligament, with the ligament in the untreated leg showing poor collagen alignment and a greater degree of scar tissue formation.
IASTM has also been reported to cause changes in the vascular response in injured soft tissues. Loghmani and Warden (2013) applied IASTM to the injured MCL of the knee in rats and found that the leg that had IASTM applied showed a significant increase in perfusion, along with the proportion of arteriole-sized blood vessels in the tibial third of the ligament, as compared with the untreated leg. Recently, Loghmani et al. (2016) reported that applying IASTM resulted in a threefold increase in the number of tissue-resident mesenchymal stem cells that exist in arterial adventitia and microvessels. The fact that fibroblasts originate from mesenchymal stem cells (Mills et al., 2013), IASTM can be considered to be closely associated with fibroblast activity. Moreover, these changes serve as evidence that IASTM can increase the blood supply to injured soft tissues by exerting a positive effect on the repair of nearby microvascular morphology. Portillo-Soto et al. (2014) indicated that applying IASTM to the human calf increased the blood flow in the area where IASTM was applied, as observed by the increase in skin temperature (from $25.83^{\circ} \mathrm{C} \pm 0$ $.30^{\circ} \mathrm{C}$ to $31.831^{\circ} \mathrm{C} \pm 0.205^{\circ} \mathrm{C}$ ).

Meanwhile, some studies have mentioned that the mechanism of action of IASTM involves restarting the healing process by causing localized inflammation in the soft tissue (Hammer, 2008; Melham et al., 1998). Poor vascularity in soft tissues due to injury acts as a factor that restricts the inflammatory response. Restriction of the inflammatory response causes disorganization or weakening of the soft tissue structure (Fredericson et al., 2005; White, 2011). On the other hand, an adequate amount of inflammation in the injured tissue can induce secretion of growth factors, which can facilitate healing by promoting stimulation of fibroblasts and collagen synthesis (Molloy et al., 2003). Moreover, based on the results from studies of the association between inflammation and fibroblasts (Molloy et al., 2003), as well as claims that IASTM can improve poor vascularity and significantly increase the number of fibroblasts (Davidson et al., 1997; Gehlsen et al., 1999; Loghmani and Warden, 2013), the inflammation hypothesis may seem plausible. However, a recent study by Vardiman et al. (2014) reported that no significant results were found when changes in the level of cytokines involved in inflammation, such as interleukin- 6 and tumor necrosis factor- $\alpha$, were observed after applying IASTM. They also found no effect on some indicators of musculoskeletal function (passive ROM, passive resistive torque, and maximum voluntary contraction peak torque). However, Vardiman et al. (2014) conducted their study in healthy males with no injuries. Unlike patients with sports injury, healthy individuals do not have inflammation. As a result, IASTM may not show any effect. To our 


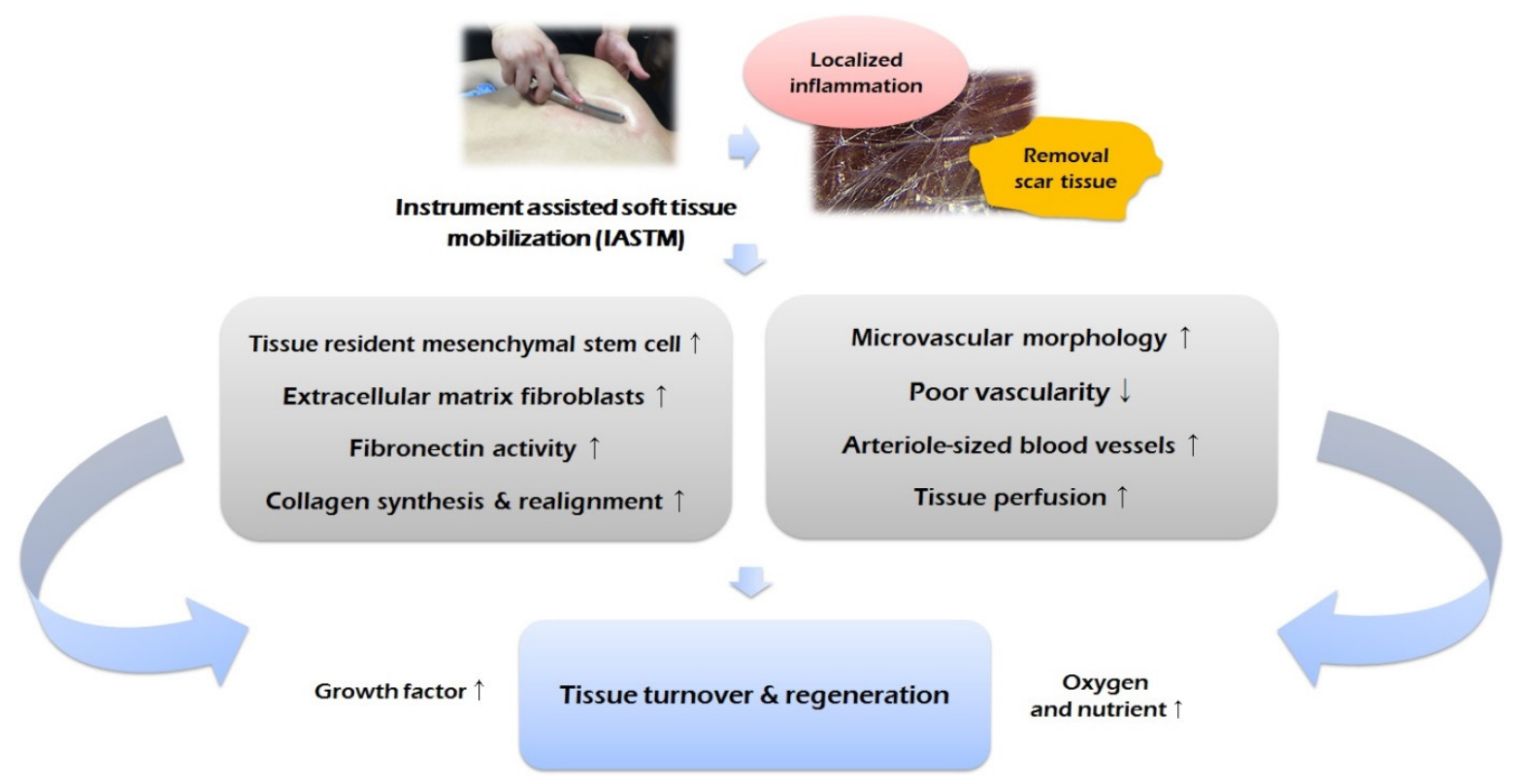

Fig. 2. Mechanism of instrument assisted soft tissue mobilization on soft tissue injury.

knowledge, the study performed by Vardiman et al. (2014) is the only one that has examined changes in inflammation following IASTM. Therefore, the inflammation hypothesis of IASTM needs to be verified further through well-designed experimental studies in patients with sports injuries. The mechanism of IASTM presented in this section is summarized in Fig. 2.

\section{Effect of IASTM}

\section{Soft tissue function}

Diminished soft tissue function following a sports injury makes it difficult to participate again in sports or activities of daily living. Therefore, recovery of soft tissue function represents one of the most important goals in sports rehabilitation. IASTM has been studied mostly in relation to tendon injuries. Previous studies have demonstrated IASTM as a treatment technique that can bring about positive changes in the recovery of soft tissue function following tendon injury. Black (2010) stated that when five sessions of IASTM were applied over a 4-week period in patients who sustained patellar tendon injury from basketball, their lower extremity functional scale (LEFS) scores improved by $23 \%-44 \%$, while Sevier and Stegink-Jansen (2015) reported that when IASTM was applied twice a week for 4 weeks in patients with lateral elbow tendinopathy, better known as tennis elbow, their DASH (disabilities of the arm, shoulder, and hand) scores decreased more than those of the eccentric exercise group and their maximum grip strength increased. Meanwhile, Park et al. (2015) reported that applying IASTM three times a week for approximately 22 days in patients hospitalized for Achilles tendinitis resulted in a significant increase in the walking distance; patients who had difficulties walking $180 \mathrm{~m}$ prior to IASTM application were able to increase their walking distance up to $390 \mathrm{~m}$ after IASTM. Moreover, Papa (2012) also indicated that when IASTM was applied for one to two sessions per week for 8 weeks as part of a rehabilitation program for patients with Achilles tendinopathy, their LEFS scores improved from 48 to 80.

Recently, McConnell et al. (2016) applied eight sessions of IASTM over a 4-week period in adults with Achilles tendinopathy and found that Young's modulus, a measure of elasticity, increased by $34.5 \%$ and stiffness increased by $31.8 \%$, while the Victorian Institute of Sport Assessment for Achilles (VISA-A) score, an index showing the severity of Achilles tendinopathy, improved from an average of 13 points to 86 points. Moreover, two subjects in particular showed VISA-A scores of $\geq 90$ points, demonstrating that they had recovered from Achilles tendinopathy. In addition, McConnell et al. (2016) also reported clinically significant changes in the functional test results of patients with Achilles tendinopathy after applying IASTM. Furthermore, a study by McCormack et al. (2016) showed that applying a combination of eccentric exercise together with IASTM for 12 weeks resulted in a greater improvement in VISA-A scores of patients with Achilles tendinopathy when compared with applying eccentric exercise alone. The fact that these improvements were sustained even at the 26th and 
52nd week of treatment is particularly noteworthy.

Chronic tendon injuries, such as tendinopathy, require lengthy management due to the physiological and anatomical characteristics of tendons and, in some cases, the patient may not respond well to treatments (Sharma and Maffulli, 2005). In comparison to muscles, tendons have lower oxygen consumption and metabolic rate and thus demonstrate slower healing after an injury (Williams, 1986). Up to now, drugs and/or physical therapy have been used for the treatment of tendinopathy, but there are conflicting opinions on their effectiveness (Andres and Murrell, 2008). Especially in the case of steroids, they may be effective for controlling pain in a patient with tendinopathy over the short term, but longterm use may have negative effects on the soft tissue function as they can delay tissue healing and further exacerbate the injury (Magra and Maffulli, 2006; Marsolais et al., 2007). In the light of this, IASTM can be considered as a good alternative for the recovery of soft tissue function following tendinopathy. Recent reports have also indicated that IASTM can be used to prevent Achilles tendinopathy. Bayliss et al. (2015) applied eight sessions of IASTM over 4 weeks in adults who had been confirmed to have a shortened Achilles tendon from a lunge test and found that their tendons showed a pattern of significant gain in Young's modulus and increase in tendon resting length than the control tendons that underwent simple stretching alone. If the Achilles tendon becomes shortened, it increases the risk of injury to the lower extremities and can progress into Achilles tendinopathy, while the running efficiency is also reduce (Bayliss et al., 2015). Therefore, increasing the Young's modulus or the resting length of shortened tendons through IASTM can not only eliminate the potential risk for Achilles tendinopathy but could also lead to a potential functional improvement.

In the meantime, some studies have reported that IASTM can also affect muscles. Faltus et al. (2012) stated that when five sessions of IASTM were applied over a period of 6 weeks in cyclist who had sustained a partial rectus femoris tear, ultrasound examination demonstrated a reduced focal lesion size, echogenicity, and hypoechoic zone around the tissue when compared with the result from early stage of treatment, while also demonstrating improved tissue continuity. After applying IASTM, morphological changes in the tissues confirmed via ultrasound examination can serve as direct evidence of musculoskeletal functional recovery, and such morphological changes have been shown to lead to improved LEFS scores (from 67 to 75). However, this study was a case report involving just one cyclist, implying that it is necessary to conduct studies with larger sample sizes. Kivlan et al. (2015) used a uni- lateral isometric squat to measure muscle performance in patients with muscular weakness from injury immediately after a single application of IASTM on lower extremity muscles. The results showed that the change in maximal force output was significantly improved in the IASTM group than in the placebo and control groups. Unlike the study by Faltus et al. (2012), the study by Kivlan et al. (2015) was able to quickly show a significant change in muscle function despite only a single application of IASTM. Regarding the potential mechanism of action, Kivlan et al. (2015) suggested an increase in fascial mobility, proliferation of extracellular matrix fibroblasts, and blood supply to the area near the injured tissue, along with a decrease in cellular matrix adhesion and localized ischemia. As already described in the "Mechanism of IASTM" section of this article, some of the hypotheses suggested by Kivlan et al. (2015) have been proven through a number of animal and human studies (Davidson et al., 1997; Loghmani and Warden, 2009, 2013; Portillo-Soto et al., 2014).

In summary, it was found that IASTM can stimulate not only tendons but also other soft tissues, such as muscles, to help improve soft tissue functions in a chronic or an acute manner. However, it is still unclear as to which extent structural and functional changes in tendons or muscles induced by IASTM can affect future injuries or prevention. Therefore, it is necessary to verify these aspects through long-term observations.

\section{Pain}

The pain reduction effects of IASTM have already been proven in some studies of musculoskeletal diseases. Lee et al. (2016) reported that when IASTM was applied for 4 weeks in 30 patients with chronic lumbar pain, the pain decreased significantly. Earlier, Howitt et al. (2006) demonstrated that applying eight treatment sessions of IASTM over 4 weeks on trigger thumb patients was helpful in reducing pain. Similar results have been found in studies of sports injury. Aspegren et al. (2007) stated that when IASTM was applied twice a week for 2 weeks in female collegiate volleyball players diagnosed with acute costochondritis, pain was reduced, enabling the players to participate in their sport again, while in a study by Daniels and Morrell (2012), pain was reduced in youth football players with plantar fasciitis by applying IASTM once a week for 6 weeks. Howitt et al. (2009) also reported that when IASTM was included in the rehabilitation program for triathletes with tibialis posterior sprain, pain was reduced 2 weeks after applying IASTM, and after 6 weeks, pain dissipated completely to allow the triathletes to participate again in running or swimming. Meanwhile, White (2011) applied one to two sessions 
of IASTM a week for 6 weeks in a 36-year-old distance runner with hamstring tendinopathy, following which the hamstring pain resolved.

Generally, pain is caused by inflammation (Proske and Allen, 2005). When an injured tissue becomes inflamed, immune cells are recruited and phagocytosis occurs. Pain is induced when tissue fragments decomposed by phagocytosis or substrates secreted by various immune cells stimulate type III and IV nerve endings (Graven-Nielsen and Mense, 2001). In particular, following a sports injury, if the injured area is not treated properly or rehabilitated adequately, then chronic inflammation may lead to tissue degeneration and become a cause of long-term pain (Franceschi and Campisi, 2014). Theoretically, control of inflammation can be considered as a potential reason for the ability of IASTM to reduce pain. Crane et al. (2012) stated that soft tissue mobilization was effective in reducing exercise-induced inflammation, but in this particular study, a massage technique, and not IASTM, was applied. However, according to a study by Vardiman et al. (2014), IASTM was found to have no effect on changes in inflammation-related factors, and pain actually increased after applying IASTM. In the study by Vardiman et al. (2014), there were no situations under which inflammation occurred. The study subjects were healthy with no inflammation and an exercise model for inducing injury was not applied. Therefore, the effects of IASTM on inflammatory changes are still unknown and this topic requires further study. Another possibility includes increased blood flow because of IASTM. Increased blood flow can quickly remove pain substrates or reduce swelling that develops around the injured tissue (Zainuddin et al., 2005). Loghmani and Warden (2013) indicated that IASTM improved perfusion, while Portillo-Soto et al. (2014) suggested that IASTM increased blood circulation. However, there is still no direct evidence of increased blood flow caused by IASTM leading to pain reduction.

\section{Range of motion}

Sufficient joint ROM is needed for optimal musculoskeletal function and insufficient flexibility can make one become vulnerable to overuse syndrome and acute injuries (Hreljac et al., 2000; Sainz de Baranda and Ayala, 2010). Therefore, having sufficient ROM is important for improving exercise performance, in addition to the rehabilitation or prevention of sports injury (Merkle et al., 2016). Some studies have suggested that IASTM can significantly improve ROM (Baker et al., 2013; Hammer and Pfefer, 2005; Kim et al., 2014; Laudner et al., 2014). Hammer and Pfefer (2005) reported that when IASTM was applied twice per week for
3 weeks in patients who had waist pain from compartment syndrome, there was an increase in hamstring flexibility, while Baker et al. (2013) applied three sessions of IASTM for 1 week on the hamstrings and triceps surae of men who had problems in the lower extremities, such as tightness and pain, which resulted in increased sit and reach $(5 \mathrm{~cm})$ and active straight leg raise $\left(7.5^{\circ}\right)$.

IASTM improves the extensibility of soft tissues by treating their restrictions (Heinecke et al., 2014), and when heat is generated from friction by the instrument, the viscosity of the tissue decreases, making it softer (Markovic, 2015). Physiologically, a decrease in the viscosity of tissue improves ROM (Ostojic et al., 2014). Meanwhile, significant changes in ROM as a result of IASTM can also be explained by hypotheses related to the nervous system. When mechanical stress is exerted on the muscle fascia, intrafascial mechanoreceptors become stimulated. This change alters the proprioceptive input sent to the central nervous system, which in turn changes the tension in tissue-related motor units (Schleip, 2003). Although it is believed that IASTM improves ROM via the mechanisms described in these hypotheses occurring independently or as a combination, scientific proof to support such claims is still lacking.

IASTM showed improvement in ROM in studies in athletes as well. Merkle et al. (2016) indicated that applying two sessions of IASTM per week for 3 weeks in healthy collegiate baseball players significantly improved their hamstring ROM, while Heinecke et al. (2014) mentioned that applying two sessions of IASTM per week for 4 weeks to the shoulder area of collegiate softball, baseball, and volleyball players was helpful in preventing a loss of ROM. Unlike some existing studies, other studies have shown a significant improvement in ROM from just a single application. Kim et al. (2014) showed improvement in ROM after a single application of IASTM in the hamstrings of adult men and women (before: $133.4^{\circ} \pm 6.7^{\circ}$, after: $146.1^{\circ} \pm 13.2^{\circ}$ ), while Laudner et al. (2014) reported that a single application of IASTM helped improve ROM in the entire shoulder area of collegiate baseball players. In the study by Laudner et al. (2014), the IASTM group $\left(11.1^{\circ}\right)$ showed significantly improved ROM when compared with the control group $\left(-0.12^{\circ}\right)$ and a significant difference in glenohumeral internal rotation ROM was also found between the $\operatorname{IASTM}\left(4.8^{\circ}\right)$ and control groups $\left(-0.14^{\circ}\right)$.

Recently, Markovic (2015) applied a single session of IASTM or foam rollers on the hips and knees of soccer players and measured their ROM via passive knee flexion and straight leg raise tests. Their results showed that, immediately after the treatment, ROM was improved more in the IASTM group than in the foam roller 
group (10\%-19\% vs. $5 \%-9 \%)$; at $24 \mathrm{hr}$ after the treatment, only the IASTM group showed improved ROM (7\%-13\%). The fact that the studies by Laudner et al. (2014) and Markovic (2015), in particular, were conducted on baseball or soccer players can be viewed as providing proof that IASTM can be applied with positive effects within a short period of time in athletes who suffer from chronic ROM restrictions. However, there is one limitation in generalizing the results from these three studies that used a single application of IASTM (Kim et al., 2014; Laudner et al. 2014; Markovic, 2015). The subjects in all the three studies did not have sports injuries and were in a healthy state. Therefore, it is necessary to investigate whether a single application of IASTM could significantly improve ROM in people with sports injuries. Meanwhile, Vardiman et al. (2014) reported that a single application of IASTM in healthy men does not affect changes in ROM. It is believed that these conflicting study results may be attributed to differences in subject characteristics, material and application protocol of the IASTM instrument, and ROM measurement positions.

\section{PRACTICAL APPLICATION FOR TREATMENT OF SOFT TISSUE}

Some previous studies have applied IASTM using the following protocols. For applying IASTM to the shoulder area, Laudner et al. (2014) had the subjects lie in the prone position on a bed and then perform shoulder abduction, $90^{\circ}$ elbow flexion, and neutral rotation after which a towel was placed below the humerus. Afterward, an instrument was placed on the muscle at a $45^{\circ}$ angle and was applied for about $20 \mathrm{sec}$ in a direction parallel to the muscle fibers, followed immediately by changing to the perpendicular direction for another $20 \mathrm{sec}$ for a total of $40 \mathrm{sec}$. For the treatment of chronic lumbar pain, Lee et al. (2016) used the same method used in the study by Laudner et al. (2014) and applied IASTM on the posterior fascia, sacrum, hip lateral rotators, and hamstring area.
Daniels and Morrell (2012) applied IASTM at an angle of $30^{\circ}$ to $60^{\circ}$ on the gastrocnemius and soleus muscles of youth football players with plantar fasciitis, while Aspegren et al. (2007) applied IASTM at an angle of $30^{\circ}$ to $60^{\circ}$ for $60-120$ sec on the chondrosternal joint and fifth costochondral segment when treating acute costochondritis in female collegiate volleyball players. In summary, when applying IASTM, an angle of $30^{\circ}$ to $60^{\circ}$ and an application time of 40-120 sec are required. These IASTM protocols were based on the manual for the Graston technique (Carey-Loghmani et al., 2010). The frequency of IASTM, in general, was one to two sessions per week for 4-5 weeks, but it may vary depending on the severity of the injury and the rehabilitation program. Previous studies also applied IASTM for about 1 to 3 times per week (Aspegren et al., 2007; Daniels and Morrell, 2012; Park et al., 2015).

In sports rehabilitation, IASTM cannot be separated and applied by itself. Soft tissue mobilization must involve both motion and strengthening to facilitate adaptation and remodeling by the tissues (Black, 2010). When IASTM is applied in sports rehabilitation, it generally goes through the following six different steps: examination, warm-up, IASTM, stretching, strengthening exercises, and cryotherapy (Table 1) (Black, 2010; Carey-Loghmani et al., 2010; Melham et al., 1998; Miners and Bougie, 2011). First, the patient's current condition must be examined accurately. The patient then needs to warm-up for 10-15 min with light jogging or using a stationary bicycle, an upper body ergometer, or an elliptical machine. At times, a hot pack or ultrasound may be applied for 3-5 min for the warm-up (Black, 2010; Hammer, 2008). This type of warm-up increases the blood supply, as well as the heating and plasticity of the tissues. IASTM begins immediately after the warm-up. The practitioner rubs a cream on the patients' skin and applies the instrument at a pressure that the patient can withstand, while finding the area to be treated with "gritty, gravelly, and sandy" types of sensations (Carey-Loghmani

Table 1. Instrument-assisted soft tissue mobilization (IASTM) treatment program for soft tissue recovery

\begin{tabular}{|c|c|c|c|}
\hline Program & Objective & Protocol & Reference \\
\hline Warm-up & $\begin{array}{l}\text { Increases the blood supply, as well as heating and } \\
\text { plasticity of the tissues }\end{array}$ & $\begin{array}{l}\text { 10-15 min with light jogging or by using } \\
\text { a stationary bicycle, upper body } \\
\text { ergometer, or elliptical machine, or } \\
3-5 \text { min with hot pack or ultrasound }\end{array}$ & Black (2010); Hammer (2008) \\
\hline IASTM & $\begin{array}{l}\text { Remove scar tissues, and facilitates synthesis and } \\
\text { realignment of new collagen }\end{array}$ & $30^{\circ}$ to $60^{\circ}$ with $40-120 \mathrm{sec}$ & Carey-Loghmani et al. (2010); Laudner et al. (2014) \\
\hline Stretching & Correct the shortened tissue, and prevent reinjury & 3 REPs with $30 \mathrm{sec}$ & Miners and Bougie (2011) \\
\hline Strengthening exercise & Strengthen the treated tissue, and prevent reinjury & High repetition with low load exercise & Hammer (2008) \\
\hline Cryotherapy & $\begin{array}{l}\text { Reduce pain, control residual inflammation, and } \\
\text { preventing secondary cell hypoxic injury }\end{array}$ & $10-20 \mathrm{~min}$ & Howitt et al. (2006); Papa (2012) \\
\hline
\end{tabular}


et al., 2010). After the completion of IASTM, stretching and muscle strengthening exercises targeting the treated area must be performed to strengthen the treated tissue and realign the collagen (Hammer, 2008). This process can help prevent reinjury to the area. Finally, cryotherapy is applied for 10-20 min (Miners and Bougie, 2011; Papa, 2012). Ice is often used for treatment of soft tissue in sports rehabilitation (Bleakley et al., 2006). Cryotherapy can reduce pain and control residual inflammation remaining in the tissue, while also preventing secondary cell hypoxic injury (Howitt et al., 2006).

Sufficient fluid intake is required before and after IASTM application. Fluid intake assists the blood supply to the injured tissue to facilitate delivery of oxygen and nutrients. In particular, when hydrogen-rich water is consumed, inflammation and oxidative stress generated from the injury can be reduced to accelerate the healing process (Tamaki et al., 2016). In addition, consuming nutritional supplements that provide amino acids, such as arginine, glutamine, and $\beta$-hydroxy- $\beta$-methyl butyrate, can also help the healing process of the injured tissue (Gündoğdu et al., 2016; Yaman et al., 2016). Other studies have used kinesio tape together with IASTM (Aspegren et al., 2007; Solecki and Herbst, 2011). Kinesio tape is an elastic tape that corrects musculoskeletal function by strengthening the weakened muscles, increases blood and lymph circulation, and reduces pain through neurologic suppression (Kase et al., 2003). Solecki and Herbst (2011) included IASTM and kinesio tape in a 12-week rehabilitation program and applied it to patients who had undergone anterior cruciate ligament surgery. The results showed recovery of muscle strength and $\mathrm{ROM}$ of the lower extremity without any complications and a drastic reduction in pain, which enabled the patients to return to their activities of daily living and sports. Therefore, clinically, the application of kinesio tape immediately following IASTM can assist the function of weakened muscles during stretching and muscle strengthening exercises, which can be useful during the rehabilitation process.

Meanwhile, the side effects that may appear from IASTM include bruising and soreness. In particular, bruising is a response that appears together with bleeding and occurs more readily in soft tissues that have been injured for a longer period of time. Bruising and soreness can be controlled with cryotherapy, following IASTM. In addition, there are relative and absolute contradictions to IASTM (Carey-Loghmani et al., 2010; Hammer, 2008). Relative contradictions include cancer, kidney dysfunction, pregnancy, rheumatoid arthritis, varicose veins, osteoporosis, lymphedema, fracture, chronic regional pain syndrome, and use of cer- tain medications (e.g., anticoagulants, steroids, or nonsteroidal anti-inflammatory drugs). Absolute contradictions include the presence of an open wound, unhealed suture sites, thrombophlebitis, uncontrolled hypertension, skin infection, hematoma, myositis ossificans, and unstable fractures. Therefore, the practitioner must be able to fully explain these issues to the patient before starting the treatment, and informed consent from the patient needs to be obtained.

\section{CONCLUSIONS}

IASTM refers to a technique that uses an instrument to remove scar tissue that had formed in soft tissues and assists in the healing process by activating fibroblasts. IASTM is simple and practical and requires only a short period of time for a single treatment. According to previous studies, IASTM was found to improve soft tissue function and ROM in acute or chronic sports injuries to soft tissues, while also reducing pain. Such positive effects can be helpful in the fields of sports rehabilitation and athletic training. However, most of the studies that supported the hypotheses concerning the mechanisms and effects of IASTM were animal studies, with very few human studies. Published articles consist mostly of case reports rather than experimental studies. Some of the case reports even failed to present the details of IASTM protocol that was applied. Therefore, the scientific basis for the mechanisms and effects of IASTM must be broadened through experimental studies in humans and the reliability of application protocol must be improved as well. Finally, to date, most of the studies concerning IASTM have focused on injuries to tendons, rather than to muscles or ligaments. Moving forward, it is necessary to provide additional proof of the effects of IASTM on muscle and/or ligaments as well.

\section{CONFLICT OF INTEREST}

No potential conflict of interest relevant to this article was reported.

\section{REFERENCES}

Andres BM, Murrell GA. Treatment of tendinopathy: what works, what does not, and what is on the horizon. Clin Orthop Relat Res 2008;466: 1539-1554.

Aspegren D, Hyde T, Miller M. Conservative treatment of a female collegiate volleyball player with costochondritis. J Manipulative Physiol 
Ther 2007;30:321-325.

Baker RT, Nasypany A, Seegmiller JG, Baker JG. Instrument-assisted soft tissue mobilization treatment for tissue extensibility dysfunction. Int J Athl The Train 2013;18:16-21.

Barata P, Cervaens M, Resende R, Camacho O, Marques F. Hyperbaric oxygen effects on sports injuries. Ther Adv Musculoskelet Dis 2011; 3:111-121.

Bayliss AJ, Crandall T, Farmer DL, Warden SJ. Instrument-assisted soft tissue mobilization alters material and mechanical properties in healthy, shortened Achilles tendons. J Orthop Sports Phys Ther 2015; 45:24.

Black DW. Treatment of knee arthrofibrosis and quadriceps insufficiency after patellar tendon repair: a case report including use of the graston technique. Int J Ther Massage Bodywork 2010;3:14-21.

Bleakley CM, McDonough SM, MacAuley DC, Bjordal J. Cryotherapy for acute ankle sprains: a randomised controlled study of two different icing protocols. Br J Sports Med 2006;40:700-705.

Burke J, Buchberger DJ, Carey-Loghmani MT, Dougherty PE, Greco DS, Dishman JD. A pilot study comparing two manual therapy interventions for carpal tunnel syndrome. J Manipulative Physiol Ther 2007; 30:50-61.

Carey-Loghmani MT, Schrader JW, Hammer WI. Graston technique: M1 instruction manual. 3rd ed. Indianapolis: Therapy Care Resources Inc.; 2010.

Chen X, Li Y. Role of matrix metalloproteinases in skeletal muscle: migration, differentiation, regeneration and fibrosis. Cell Adh Migr 2009; 3:337-341.

Chiu JY, Gau ML, Kuo SY, Chang YH, Kuo SC, Tu HC. Effects of Gua-Sha therapy on breast engorgement: a randomized controlled trial. J Nurs Res 2010;18:1-10.

Church RL, Pfeiffer SE, Tanzer ML. Collagen biosynthesis: synthesis and secretion of a high molecular weight collagen precursor (procollagen). Proc Natl Acad Sci U S A 1971;68:2638-2642.

Costello JT, Baker PR, Minett GM, Bieuzen F, Stewart IB, Bleakley C. Whole-body cryotherapy (extreme cold air exposure) for preventing and treating muscle soreness after exercise in adults. Cochrane Database Syst Rev 2015;(9):CD010789.

Crane JD, Ogborn D, Cupido C, Melov S, Hubbard A, Bourgeois JM, Tarnopolsky MA. Massage therapy attenuates inflammatory signaling after exercise-induced muscle damage. Sci Transl Med 2012;4:119ra13.

Daniels CJ, Morrell AP. Chiropractic management of pediatric plantar fasciitis: a case report. J Chiropr Med 2012;11:58-63.

Davidson CJ, Ganion LR, Gehlsen GM, Verhoestra B, Roepke JE, Sevier TL. Rat tendon morphologic and functional changes resulting from soft tissue mobilization. Med Sci Sports Exerc 1997;29:313-319.
Davies CC, Backopp DY. Use of Astym treatment on scar tissue following surgical treatment for breast cancer: a pilot study. Rehabil Oncol 2010;28:3-12.

Delbari A, Bayat M, Bayat M. Effect of low-level laser therapy on healing of medial collateral ligament injuries in rats: an ultrastructural study. Photomed Laser Surg 2007;25:191-196.

Faltus J, Boggess B, Bruzga R. The use of diagnostic musculoskeletal ultrasound to document soft tissue treatment mobilization of a quadriceps femoris muscle tear: a case report. Int J Sports Phys Ther 2012;7: 342-349.

Franceschi C, Campisi J. Chronic inflammation (inflammaging) and its potential contribution to age-associated diseases. J Gerontol A Biol Sci Med Sci 2014;69 Suppl 1:S4-9.

Fredericson M, Moore W, Guillet M, Beaulieu C. High hamstring tendinopathy in runners: meeting the challenges of diagnosis, treatment, and rehabilitation. Phys Sportsmed 2005;33:32-43.

Gauglitz GG, Korting HC, Pavicic T, Ruzicka T, Jeschke MG. Hypertrophic scarring and keloids: pathomechanisms and current and emerging treatment strategies. Mol Med 2011;17:113-125.

Gehlsen GM, Ganion LR, Helfst R. Fibroblast responses to variation in soft tissue mobilization pressure. Med Sci Sports Exerc 1999;31:531535.

Graven-Nielsen T, Mense S. The peripheral apparatus of muscle pain: evidence from animal and human studies. Clin J Pain 2001;17:2-10.

Gündoğdu RH, Temel H, Bozkırlı BO, Ersoy E, Yazgan A, Yıldırım Z. The mixture of arginine, glutamine, and $\beta$-hydroxy- $\beta$-methyl butyrate enhances the healing of ischemic wounds in rats. JPEN J Parenter Enteral Nutr 2016 Jan 29 [Epub]. pii: 0148607115625221.

Hammer WI. The effect of mechanical load on degenerated soft tissue. J Bodyw Mov Ther 2008;12:246-256.

Hammer WI, Pfefer MT. Treatment of a case of subacute lumbar compartment syndrome using the Graston technique. J Manipulative Physiol Ther 2005;28:199-204.

Hart LE. Exercise and soft tissue injury. Baillieres Clin Rheumatol 1994;8:137-148.

Hayes D, Loghmani MT, Lubitz R, Moore E. A comparison of 2 instrument-assisted soft tissue mobilization techniques: effects on therapist discomfort/fatigue and treatment time [abstract]. J Orthop Sports Phys Ther 2007;37. Abstract No. OPL19.

Heinecke ML, Thuesen ST, Stow RC. Graston technique on shoulder motion in overhead athletes. J Undergrad Kinesiol Res 2014;10:27-39.

Howitt S, Jung S, Hammonds N. Conservative treatment of a tibialis posterior strain in a novice triathlete: a case report. J Can Chiropr Assoc 2009;53:23-31.

Howitt S, Wong J, Zabukovec S. The conservative treatment of Trigger 
thumb using Graston Techniques and Active Release Techniques. J Can Chiropr Assoc 2006;50:249-254.

Hreljac A, Marshall RN, Hume PA. Evaluation of lower extremity overuse injury potential in runners. Med Sci Sports Exerc 2000;32:16351641.

Huard J, Li Y, Fu FH. Muscle injuries and repair: current trends in research. J Bone Joint Surg Am 2002;84-A:822-832.

Inoue M, Nakajima M, Oi Y, Hojo T, Itoi M, Kitakoji H. The effect of electroacupuncture on tendon repair in a rat Achilles tendon rupture model. Acupunct Med 2015;33:58-64.

Kase K, Wallis J, Kase T. Clinical therapeutic applications of the kinesio taping method. Tokyo: Ken Ikai Co. Ltd.; 2003.

Kim DH, Kim TH, Jung DY, Weon JH. Effects of the Graston technique and self-myofacial release on the range of motion of a knee joint. J Korean Soc Phys Med 2014;9:455-463.

Kivlan BR, Carcia CR, Clemente FR, Phelps AL, Martin RL. The effect of Astym ${ }^{\circledR}$ Therapy on muscle strength: a blinded, randomized, clinically controlled trial. BMC Musculoskelet Disord 2015;16:325.

Laudner K, Compton BD, McLoda TA, Walters CM. Acute effects of instrument assisted soft tissue mobilization for improving posterior shoulder range of motion in collegiate baseball players. Int J Sports Phys Ther 2014;9:1-7.

Lee JH, Lee DK, Oh JS. The effect of Graston technique on the pain and range of motion in patients with chronic low back pain. J Phys Ther Sci 2016;28:1852-1855.

Lehto M, Duance VC, Restall D. Collagen and fibronectin in a healing skeletal muscle injury. An immunohistological study of the effects of physical activity on the repair of injured gastrocnemius muscle in the rat. J Bone Joint Surg Br 1985;67:820-828.

Lenselink EA. Role of fibronectin in normal wound healing. Int Wound J 2015;12:313-316.

Loghmani MT, Fuller EM, Handt R, Neff B, Seasly L, Swartz C, Witted M, March KL. Instrument-assisted soft tissue mobilization in healthy young adult males mobilizes tissue-resident mesenchymal stem cells into circulation. J Orthop Sports Phys Ther 2016;46:107.

Loghmani MT, Warden SJ. Instrument-assisted cross-fiber massage accelerates knee ligament healing. J Orthop Sports Phys Ther 2009;39:506514.

Loghmani MT, Warden SJ. Instrument-assisted cross fiber massage increases tissue perfusion and alters microvascular morphology in the vicinity of healing knee ligaments. BMC Complement Altern Med 2013;13:240.

Magra M, Maffulli N. Nonsteroidal antiinflammatory drugs in tendinopathy: friend or foe. Clin J Sport Med 2006;16:1-3.

Markovic G. Acute effects of instrument assisted soft tissue mobilization vs. foam rolling on knee and hip range of motion in soccer players. J Bodyw Mov Ther 2015;19:690-696.

Marsolais D, Côté CH, Frenette J. Pifithrin-alpha, an inhibitor of p53 transactivation, alters the inflammatory process and delays tendon healing following acute injury. Am J Physiol Regul Integr Comp Physiol 2007;292:R321-327.

McConnell J, Cruser S, Warden SJ, Bayliss AJ. Instrument-assisted soft tissue mobilization alters material and mechanical properties in Achilles tendinopathy. J Orthop Sports Phys Ther 2016;46:114.

McCormack JR, Underwood FB, Slaven EJ, Cappaert TA. Eccentric exercise versus eccentric exercise and soft tissue treatment (Astym) in the management of insertional achilles tendinopathy. Sports Health 2016; 8:230-237.

Melham TJ, Sevier TL, Malnofski MJ, Wilson JK, Helfst RH Jr. Chronic ankle pain and fibrosis successfully treated with a new noninvasive augmented soft tissue mobilization technique (ASTM): a case report. Med Sci Sports Exerc 1998;30:801-804.

Merkle TP, Beckmann N, Bruckner T, Zeifang F. Shoulder joint replacement can improve quality of life and outcome in patients with dysmelia: a case series. BMC Musculoskelet Disord 2016;17:185.

Mills SJ, Cowin AJ, Kaur P. Pericytes, mesenchymal stem cells and the wound healing process. Cells 2013;2:621-634.

Miners AL, Bougie TL. Chronic Achilles tendinopathy: a case study of treatment incorporating active and passive tissue warm-up, Graston Technique, ART, eccentric exercise, and cryotherapy. J Can Chiropr Assoc 2011;55:269-279.

Molloy T, Wang Y, Murrell G. The roles of growth factors in tendon and ligament healing. Sports Med 2003;33:381-394.

Nielsen A, Knoblauch NT, Dobos GJ, Michalsen A, Kaptchuk TJ. The effect of Gua Sha treatment on the microcirculation of surface tissue: a pilot study in healthy subjects. Explore (NY) 2007;3:456-466.

Ostojic SM, Vukomanovic B, Calleja-Gonzalez J, Hoffman JR. Effectiveness of oral and topical hydrogen for sports-related soft tissue injuries. Postgrad Med 2014;126:187-195.

Papa JA. Conservative management of Achilles Tendinopathy: a case report. J Can Chiropr Assoc 2012;56:216-224.

Park JH, Oh EY, Lee HJ, Kim YJ, Shin YB. A case report on a patient of Achilles tendinitis treated with Gyeon-mak chuna, Korean medicine and Grasaton Technique. J Korean Acad Rehabil Med 2015;25:103-110.

Portillo-Soto A, Eberman LE, Demchak TJ, Peebles C. Comparison of blood flow changes with soft tissue mobilization and massage therapy. J Altern Complement Med 2014;20:932-936.

Proske U, Allen TJ. Damage to skeletal muscle from eccentric exercise. Exerc Sport Sci Rev 2005;33:98-104.

Sainz de Baranda P, Ayala F. Chronic flexibility improvement after 12 
week of stretching program utilizing the ACSM recommendations: hamstring flexibility. Int J Sports Med 2010;31:389-396.

Sato K, Li Y, Foster W, Fukushima K, Badlani N, Adachi N, Usas A, Fu $\mathrm{FH}$, Huard J. Improvement of muscle healing through enhancement of muscle regeneration and prevention of fibrosis. Muscle Nerve 2003;28:365-372.

Schaefer JL, Sandrey MA. Effects of a 4-week dynamic-balance-training program supplemented with Graston instrument-assisted soft-tissue mobilization for chronic ankle instability. J Sport Rehabil 2012;21:313326.

Schleip R. Fascial mechanoreceptors and their potential role in deep tissue manipulation. J Bodyw Mov Ther 2003;7:104-116.

Sevier TL, Stegink-Jansen CW. Astym treatment vs. eccentric exercise for lateral elbow tendinopathy: a randomized controlled clinical trial. Peer] 2015;3:e967.

Sharma P, Maffulli N. Tendon injury and tendinopathy: healing and repair. J Bone Joint Surg Am 2005;87:187-202.

Solecki TJ, Herbst EM. Chiropractic management of a postoperative complete anterior cruciate ligament rupture using a multimodal approach: a case report. J Chiropr Med 2011;10:47-53.

Steinacker T, Steuer M. Use of extracorporeal shockwave therapy (ESWT) in sports orthopedics. Sportverletz Sportschaden 2001;15:45-49.

Tamaki N, Orihuela-Campos RC, Fukui M, Ito HO. Hydrogen-rich water intake accelerates oral palatal wound healing via activation of the Nrf2/antioxidant defense pathways in a rat model. Oxid Med Cell Longev 2016;2016:5679040.

Topol GA, Reeves KD, Hassanein KM. Efficacy of dextrose prolotherapy in elite male kicking-sport athletes with chronic groin pain. Arch Phys Med Rehabil 2005;86:697-702.

Vardiman JP, Siedlik J, Herda T, Hawkins W, Cooper M, Graham ZA, Deckert J, Gallagher P. Instrument-assisted soft tissue mobilization: effects on the properties of human plantar flexors. Int J Sports Med 2014;36:197-203.

White KE. High hamstring tendinopathy in 3 female long distance runners. J Chiropr Med 2011;10:93-99.

Williams JG. Achilles tendon lesions in sport. Sports Med 1986;3:114-135.

Yaman F, Acikan I, Dundar S, Simsek S, Gul M, Ozercan IH, Komorowski J, Sahin K. Dietary arginine silicate inositol complex increased bone healing: histologic and histomorphometric study. Drug Des Devel Ther 2016;10:2081-2086.

Yeung EW, Yeung SS. A systematic review of interventions to prevent lower limb soft tissue running injuries. Br J Sports Med 2001;35:383389.

Zainuddin Z, Newton M, Sacco P, Nosaka K. Effects of massage on delayed-onset muscle soreness, swelling, and recovery of muscle function.J Athl Train 2005;40:174-180. 